\title{
28 Research Suare \\ Roaming Dogs in Ushuaia City, Tierra Del Fuego, Argentina. How Many and Why
}

\section{Emiliano Arona ( $\nabla$ emi.arona18@gmail.com )}

Universidad Nacional de Tierra del Fuego Antartida e Islas del Atlantico Sur https://orcid.org/00000003-4702-8863

\section{Adrián Schiavini}

CADIC: Centro Austral de Investigaciones Cientificas

\section{Research Article}

Keywords: free roaming dogs, abundance estimation, mark recapture, modeling, abundance index.

Posted Date: November 30th, 2021

DOl: https://doi.org/10.21203/rs.3.rs-282341/v1

License: (1) This work is licensed under a Creative Commons Attribution 4.0 International License. Read Full License 


\section{Abstract}

Free roaming dogs (FRD) in cities represent an increasing problem. Authorities need numbers of FRDs to evaluate policies implemented and to monitor the dog population.

We estimated the number of FRD in Ushuaia city, Argentina, using a photographic capture-recapture methodology. We estimated an abundance index, the power to detect changes in the index, and modeled factors that may explain the spatial distribution of FRD and their welfare status.

During three surveys, covering 72 transects along streets ( $9.9 \%$ of the street layout of Ushuaia), we recorded 539 different FRDs. A model with individual heterogeneity in capture-recapture probability gave 12,797 FRDs (95\% Cl 10,979 - 15,323), reflecting a dog:human relation of 1:6, higher than the relation recommended by the WHO. The abundance index was similar between surveys $(8.13 \pm 1.36,8.38 \pm 1.46$ and $9.55 \pm 1.28 \mathrm{dogs} / \mathrm{km}$ ). The difference needed to detect changes in the index is about twice the standard error of estimates.

The best model explaining dogs' abundance included only geographical location, although two neighbourhoods with 9 transects stand out with 181 different FRDs identified. Together with the good overall dogs' welfare status, modeling suggests that the behavior of owners is the main driver for the presence of FRDs.

We recommend the use of photographic capture-recapture methodologies instead of simple index estimation, due to the small additional effort required and the improved accuracy and precision obtained. We also recommend a permanent systematic design for future surveys, increase the number of survey occasions, and improve the survey process.

\section{Introduction}

The domestic dog represents an especially important part of human culture today, and most of the dogs are kept by people for company. Currently, the domestic dog represents the most abundant carnivore on the planet, estimated at 1,000 million individuals. The large number of dogs kept by people for company is not accompanied by responsible keeping. Besides, the growing tendency of society to live in cities produces a growing amount of free roaming dogs on the streets.

Ushuaia is a city located in the Argentine portion of the Isla Grande de Tierra del Fuego, at the southernmost tip of South America. Currently it holds about 75,000 inhabitants (Molpeceres 2017). Different industrial promotion policies started by the 1970 s led to a fast population growth, mainly caused by internal immigration. Similarly, the population of dogs increased. Free roaming dogs are a public health and environmental nuisance because of attacks and bites to people, defecation and urination on the streets, garbage dispersion and harassment and killing to other animals (Zanini et al. 2008, Schiavini and Narbaiza 2015). The different policies implemented by the city, focused in promote responsible tenure by identification, vaccination and spaying of animals, are up to date inefficient to 
reduce the number of dogs on streets. There are no accurate numbers about the population size of dogs in the city of Ushuaia. Surveys in elementary schools, adjusted for the number of users of the electric service, revealed in 2016 that Ushuaia holds a total of 31,992 owned dogs and that $60 \%$ of households let dogs roam sometime during the day, either by itself or accompanied by somebody (Garber 2016).

Estimates of numbers and characteristics of roaming dogs is one of the key indicators for planning and monitoring the success of interventions to reduce the amount of dogs on the streets (Hiby et al. 2017), for managing risks linked with them (Dias et al. 2013) and to understand the prevalence of zoonosis. Several methods are being used to estimate the number of roaming dogs (see a complete revision in Belo et al. 2015). Many of them are inspired in methods used for surveying the abundance of natural animal populations (see Sutherland 2006) but adapted to the cities, as direct counts of animals, distance-based methods, and capture-recapture of dogs. Two especially important points are usually disregarded when estimating the number of free roaming dogs in streets: the design of sampling and the detection probability of dogs.

The sampling design is the procedure for selecting the number of samples and how to arrange them in the study area so that the results are as reliable as possible. Cochran (1977), Thompson (2002) and Williams et al. (2002), among many other authors, provide technical accounts of this topic. In summary, when surveying part of a city, results from the surveyed portion are extrapolated to the rest of city. Counts (either direct counts, distance-based methods or capture recapture studies) are normally done traversing parts of the street layout of the city and recording the observed animals. Data are later analyzed by several methods as simple averages of counts per distance unit, distance-based analysis or capture recapture techniques. These design-based estimations requires that every part of the city has the same coverage probability of being sampled, that is, that every street block has the same probability of being included in the sampled portion. Otherwise, parts of the city may never be reached by sampling, biasing the results and the conclusions obtained. Many approaches for randomization of designs are used to ensure that these assumptions are met and can be found in the abovementioned references. Besides, when deciding how many streets or pieces of streets to sample, there is a tradeoff between spending a large effort to gain accuracy or precision in the estimate or get redundant information that doesn't adds to neither accuracy nor precision.

When sampling animal populations, random sampling alone do not guarantee reliable sample-based estimators, because sampled units usually underrepresent the actual number of animals present on the units at the time of the survey, producing systematic errors in sample-based estimators. These detectability issues affect accuracy of estimation and deserve attention if the objective is to estimate the numbers instead of giving an index of abundance. Capture recapture methodologies are widely used methodologies to study several population parameters (Amstrup et al. 2002, Williams et al. 2002), that include both open and closed populations. Direct counts of dogs on streets assume that all dogs present on the streets are detected by observers during the survey, i.e. that the probability of detection equals 1 , an assumption rarely tested. Instead, capture-recapture studies allow estimating the detection probability of animals and provide a much accurate estimator of abundance. 
When the objective is to assess changes in number of roaming dogs, an index of abundance can be enough. Indexes do not need to correct for the detection probability and can be easier to record and estimate because do not require photographic identification and several surveys. Hiby and Hiby (2017) advocate for the use of such indexes when the question is if dogs on the streets increase or decrease after an intervention. However, indexes are not excused of design issues. If the city is sampled for an index estimation, the requirements for the sample to be representative stands.

In this paper, we present an estimation for roaming dog population in Ushuaia, based in a two-step procedure: first, we define a proper design aimed to get an even coverage probability, and second, we estimate the abundance of dogs based on a capture recapture technique applied to this sample. We also provide an abundance index and assess the power to detect changes in the index for future surveys. We also explore factors that may explain the spatial distribution of dogs along the city. Furthermore, this paper provides tools and recommendations to the city of Ushuaia to assess the abundance of roaming dogs and to monitor their numbers in the future.

\section{Headings}

- By photographic capture recapture we estimated 12,797 free roaming dogs for Ushuaia.

- There was strong spatial heterogeneity in the spatial distribution of free roaming dogs.

- The main driver for free roaming dogs on the streets would be the behaviour of owners.

- Capture recapture estimations outperforms abundance index at a slightly higher effort.

\section{Materials And Methods}

\subsection{Study Area}

The study was carried out in the Ushuaia city $\left(54^{\circ} 49^{\prime} S-68^{\circ} 19^{\prime} \mathrm{W}\right)$, located in the Argentine sector of the Isla Grande de Tierra del Fuego, the capital city of the province of Tierra del Fuego, Antártida e Islas del Atlántico Sur (Fig. 1). The city develops along the coast of the Beagle Channel and is bounded by the slopes of the Andean range, covering about $12 \mathrm{~km}$ in its main axe and a surface of about $23 \mathrm{~km}^{2}$. The population was estimated at 75,000 inhabitants by 2015 (Molpeceres 2017).

The sampled area corresponded to the road plot available at OpenStreetMap, which excludes some sectors of recent development of about $2.5 \mathrm{~km}^{2}$. This road plot covers $252 \mathrm{~km}$ of streets. Free roaming dogs on the street recorded in this paper comprise dogs with owners who let them roam by themselves and homeless dogs without owners or keepers (partially supervised and unsupervised dogs).

\subsection{Survey design}

The survey was designed with the philosophy of population assessment by distance sampling (Buckland et al. 1992). In a simplification, the survey runs along lines from which objects of interest and their 
distance from the line are recorded. The analysis models the decay of the detection probability with distance from the line to estimate the probability of sighting an individual over the line, and estimates density combining the number of sightings based on the distance travelled (encounter rate) and the group size (if individuals get together). In our study we used a strip transect, a special case where the probability of detection is constant along the transects in a fixed band, with the transects corresponding to the streets and the bandwidth defined as $14 \mathrm{~m}$, the width of the sidewalks and the street added, which represents the space where roaming dogs can move freely.

The number and length of the transects to survey represents the sampling effort. To assess the effort and its spatial distribution required for uniform coverage, we used the simulation module of the DISTANCE software, which allows to compare the coverage of different designs. The program simulates a grid of points in the study area, over which different designs are applied. The tested designs were limited to what are called "segmented track lines": parallel streets running from the coast to uphill, segmented in surveyed and not surveyed segments. Two types of designs, available in DISTANCE, were tested: a systematic segmented track line sampling that distributes randomly a systematic set of segments, and a systematic segmented grid sampling that distributes segments based on a set of grid points in a regular pattern.

The use of segmented transects a) increases the number of samples, allowing spatial heterogeneity to be better explored than with continuous transects, $b$ ) reduces observer fatigue, allowing rest of the surveyors during non-sampled segments, c) reduces total effort in relation to sample continuous transects and d) traveling complete transects from the coast to the mountains would be difficult because of the layout of the city streets.

The simulated grid represented a grid of street intersections separated at a distance of $100 \mathrm{~m}$, representing the modal distance between intersections in Ushuaia. Simulated transects run in a general direction from the coast to the mountain slopes, to explore the effect of environmental covariates related to height or distance to city borders. At each simulation, transects are laid over the grid and the software records how many points of the grid are touched by the transects and returns statistics of these so called "hits". After a number of simulations, 1000 in this study, it is expected that an even coverage probability is represented by a low variability in the average coverage probability and with all the points of the grid "touched" by a transect. Although there is not an "objective measure of evenness", designs with minimum numbers of hits equal to zero and larger standard deviations of the average coverage probability should be discarded.

As one of the objectives of this study is to provide managers with a tool for future surveys or monitor efforts, the final selection of the design should also consider logistic criteria, as the total effort needed and the future feasibility of a design to be performed with low need of training. This favors the selection of a design to be established as a set of permanent transects that would be subsequently monitored to detect changes in roaming dogs' abundance. We simulated designs with different segment length and transect separation (Supplemental Material S1). The selected design was based on the effort to be 
developed and the lower relative standard deviation of the coverage probability (Supplemental Material S1).

The simulated designs are based on a city with a checkerboard street layout. For a city without this street layout, the selected design must be adapted to the actual street layout. For that, the design was superimposed over the street layout with a Geographical Information System ArcGis 10.7 and street blocks were selected as the segments to survey, based on their length and proximity to the designed segments and on the general direction from the sea uphill for all the segments.

\subsection{Abundance estimation}

For the estimation of abundance we used the photographic capture-recapture first used by Beck (1973), which represents a modification of the classic capture-recapture method of Lincoln and Petersen (1930), in turn modified by Schnabel (1938) for multiple sampling occasions. This methodology does not require physically capture of dogs to mark them. In its original development, the methodology assumes that (1) the capture of the animal does not affect its subsequent probability of recapture, (2) all animals have the same probability of being captured on an occasion, (3) the population is closed during the sampling period and (4) the marks are not lost during the study. Further developments replaced the first two assumptions by models that account for variation in capture probabilities due to capture, occasions or individual behavior (Otis et al. 1978), some of them used in this study.

Street segments were travelled by car at a speed of $10 \mathrm{~km} / \mathrm{h}$ with one surveyor with a photographic camera at each side. All dogs seen on the street, or inside a house parcel but free to move to the street were photographed. A third surveyor recorded the dogs seen to have a direct count of dogs on streets. A body condition index of dogs was registered, using a scale of 1 to 3 , based on body fat coverage as underweight, ideal weight, and overweight, respectively, a modification of the categories described by WSAVA (2011) and ICAM Coalition (2015) allowing robust remote registration. The presence of visible injuries was also recorded, as well as the presence of collars or other kind of accessory, as a proxy of evidence for tenure.

Three surveys were performed, between 10 AM to 7 PM, during three consecutive Saturdays (October 12th, 19th and 26th of 2019). Due the bad weather conditions on the second Saturday, the survey was completed in Sunday. The day of the week and time of the day was chosen after free interviews with people that interact with dogs during their work as postmen, garbage collectors and a member of a dog protection organization. Saturday was selected also because people know that dog catchers are not active during weekends. After the surveys, individual dogs were identified in each segment and occasion, based on phenotypic characters like color, patches, size. The "history of capture/recapture" of each identified dog was built, like dogs seen on the three surveys, dogs seen only in one of the surveys, and all the possible combinations among the three surveys.

The capture-recapture history was analyzed using maximum likelihood estimators for closed populations to assess the probability of capture and recapture with the MARK software (White y Burnham 1999), 
including models from the CAPTURE software (White et al. 1978), software with a long history of use in wildlife demography studies. Detectability is equivalent to the probability of capture and the probability of recapture in this study, since the photographed dogs were "captured" and "recaptured" without being physically trapped. From this information the probability of detection of dogs was assessed.

Four models that account for the heterogeneity in detectability (Otis et al. 1978) were tested:

- Null model $\left(M_{0}\right)$ : detectability remains constant between sampling occasions and individuals.

- Temporal heterogeneity $\left(M_{t}\right.$ model): detectability varies between sampling occasions, but is constant among animals at each sampling occasion.

- Behavior heterogeneity $\left(M_{b}\right.$ model): detectability of an animal changes after its first capture, either by avoiding or being attracted to the recapture situation.

- Individual heterogeneity $\left(M_{h}\right.$ model): each animal has a unique detectability throughout the capture occasions.

Models were compared using a theoretic information approach, by means of the Akaike Information Criterion corrected for small samples (AIC $C_{c}$ Akaike 1973). Estimations based on the best model were extrapolated to the whole street layout of the city.

\subsection{Index of abundance}

The three surveys provided an index of abundance, as the number of animals seen at each occasion, averaged over the street segments of each survey.

An index is valuable if it allows to detect changes in numbers and, obviously, assumes perfect detectability of dogs seen on the streets during a survey. Following Hiby and Hiby (2017), the differences between the densities recorded in each transect for two surveys done using the same transects, averaged over the transects and then divided by their standard error, follows a Student's $t$ distribution with $n-1$ degrees of freedom, where $n$ equals the number of transects. If this quotient presents a probability less than 0.05 in a Student's $t$ distribution, then the average density between surveys is significantly different at the $95 \%$. Therefore, using the Solver tool of Microsoft Excel, we can estimate how much the average density should differ in a future survey to detect a significant change in density for different levels of standard error.

\subsection{Factors affecting dog abundance}

The total number of different dogs identified at each transect (the sum of different dogs identified in the 3 surveys for each transect) was used as a response variable to model the factors that would affect the presence of roaming dogs in streets. This number represents the "minimum" number of dogs present in the transect, and is more representative of the average behavior of dog owners, who let dogs roam freely during some time of the day, than the counts for each one of the three surveys.

The covariates considered were: 
- Number of houses in each transects. At apartment buildings the main entrance door to the building was recorded and the number of dwellings was estimated accounting for an average of three households per floor.

- Availability of food resources, using as a proxy the number of waste containers in each transect.

- Number of properties in each transect with effective fences against the free movement of dogs to the street.

- Presence of "shelters", using as a proxy the distance from the midpoint of the transect to the city limit.

- Geographic location at the midpoint of the transect.

- Height above sea level at the midpoint of the transect (taken from the Digital Elevation product, Shuttle Radar Topography Mission,1 Arc-Second Global, 30 m resolution, from the page https://earthexplorer.usgs. gov).

Collinearity of covariates was checked examining the Variance Inflation Factor (VIF) of each covariate, using the package car (v.3.0-6; Fox and Weisberg, 2019) for R software. Covariates whose VIF was > 3 should be removed from modelling (Zuur et al. 2010).

The relationship between the dog counts and the covariates was explored by means a Generalized Additive Model (Wood 2017) with a Poisson family of errors. As transects differed in length, the logarithm of the length of each transect was added as an offset variable in all the models analyzed. The degree of support to the different models was assessed using a multimodel inference approach (Anderson and Burnham 2004) based on the corrected $\mathrm{AIC}_{\mathrm{c}}$, using the model.sel() function of the MuMIn R package (Barton 2019). The smoothing functions for each covariate used $k=10$ nodes or splines $(k)$ for the geographical position as usual practice for geographical covariates (Wood 2017), and $k=3$ for the rest of the predictor variables, this value being the minimum number of nodes that additive modelling accepts. To account for the complexity of the shape of Ushuaia city when modelling the geographic position, we used the "soap film smoother" (Wood et al. 2008) included in the GAM routine. The GAM also allowed to get a representation of the relative spatial distribution of dog counts, by graphing the smoothing surface for geographic coordinates, using the function vis.gam() of the R package mgcv (Wood 2019).

\section{Results}

\subsection{Record of data}

Each survey comprised a total of $25 \mathrm{~km}$ covered in 72 transects. From the 996 photographs taken, a total of 211 dogs were photographed in the first survey, 221 in the second and 240 in the last. A total of 511 different dogs were identified from the pictures. Apart from this, 28 specimens were recorded but could not be photographed and identified (15, 9 and 4 for the first, second and third survey respectively). As their proportion was $5.2 \%$ of the total, these individuals were considered "new" dogs for analytical 
purposes (not previously or subsequently identified), since having withdrawn those from the analysis would have underestimated the results. Consequently, 539 different dogs were registered for the analysis.

The visible welfare records for the three surveys revealed that most of the dogs presented ideal weight (60\%,76\% and $86 \%$ respectively), followed by individuals showing overweight $(7 \%, 14$ and $9 \%$ respectively) and underweight ( $4 \%, 5 \%$ and $1 \%$ respectively). The number of unrated dogs $(29 \%, 5 \%$ and $4 \%$ respectively) came from animal that escaped prior to record or were lying down or in a position that made it difficult to classify. Injuries were infrequent ( $2 \%, 4 \%$ and $1 \%$ respectively), and dogs presented a collar or other accessory as a sign of tenure in $12 \%, 24 \%$ and $17 \%$ of the cases respectively.

\subsection{Abundance and index of abundance}

Program MARK returned model $M_{h}$ as the best model, far apart from the rest of the models based on the $\triangle \mathrm{AIC}_{\mathrm{c}}$ (Supplemental Material S2). Thus, the abundance of roaming dogs for the sampled streets was 1,267 individuals $(95 \% \mathrm{Cl} 1,081-1,517)$. As the study area presents approximately $252 \mathrm{~km}$ of streets, and the surveyed route represented $9.9 \%$ of the total, the roaming dog population of Ushuaia is estimated at 12,797 individuals $(95 \% \mathrm{Cl} 10,979-15,323)$.

The abundance index, as the mean densities ( \pm standard error) of roaming dogs for each survey (dogs $/ \mathrm{km}$ ), presented considerable standard errors, due to the heterogeneity in encounter rates of dogs between transects on each occasion $(8.13 \pm 1.36,8.38 \pm 1.46$ and $9.55 \pm 1.28$ for the first, second and third survey respectively). Mean densities between sampling occasions were not significant different at the $95 \%$ (two tailed paired $t$-test: $p=0.83 p=0.09, p=0.16$ comparing surveys 1 to 2,1 to 3 and 2 to 3 )

The level of change in density needed to detect changes in the abundance index between two surveys depends on the standard errors of the differences between surveys. Using the same 72 transects, the difference in density of dogs from which a significant change in the population could be detected varies between 0.8 and 4 individuals per linear kilometer (Table 1), representing approximately twice the standard error between surveys. 
Table 1

Level of difference in average density between surveys, needed to detect changes in the density of roaming dogs, based on the standard error of the differences between surveys.

\begin{tabular}{|ll|}
\hline Standard Error & Change in density required in relation to a previous survey $(\mathrm{dogs} / \mathrm{km})$ \\
\hline 0.4 & 0.80 \\
0.6 & 1.20 \\
0.8 & 1.60 \\
1.0 & 1.99 \\
1.2 & 2.39 \\
1.4 & 2.79 \\
1.6 & 3.19 \\
\hline 1.8 & 3.59 \\
\hline 2.0 & 3.99 \\
\hline
\end{tabular}

\subsection{Factors affecting dog abundance}

The analysis revealed a high correlation among the number of houses, waste containers and fences. Despite that, as the multicollinearity analysis revealed that none of the covariates exceeded the 3 units of the Variance Inflation Factor, all of them were included in the models. A total of 16 models were tested (Supplemental Material S3) and ranked according to the $\mathrm{AlC}_{\mathrm{c}}$ value. The best model included only the geographic location, with an Akaike weight of 0.91 . The remaining models presented a $\triangle \mathrm{AlC}_{\mathrm{C}}>2$ and therefore little support with respect to the best model.

\subsection{Spatial distribution of free roaming dogs}

The city presented spatial heterogeneity in the number of roaming dogs, both for each survey as well as for the sum of different dogs from the three surveys (Fig. 2), although areas with the largest numbers were the same along the three surveys. The smoothing of the geographical position in the GAM (Fig. 3) also reveals areas of large numbers of roaming dogs, with the smallest number of dogs in downtown. There was not evident spatial heterogeneity in the number of houses, but the number of containers and fences are lower in the most peripheral neighborhoods (Supplemental Material S4).

\section{Discussion}

The amount of dogs in a good body condition, the scarcity of dogs with skin conditions or injuries and the number of dogs carrying collars or other accessories, suggests that the roaming dogs in the streets of 
Ushuaia are mostly represented by owned dogs partially supervised. This is consistent with the weakness in the explanation power of the factors to explain dog distribution and abundance as it is be explained further in the text.

The non-identification of dogs because no photographs could be taken or because the quality of the pictures is low leads to uncertain identifications (Belo et al. 2015). In this work, multiple photographs of each individual were available, allowing for easy recognition. Previous works using the same methodology do not present details on the building of the capture history (Daniels and Bekoff 1986; Özen et al. 2016; Hu et al. 2019), the success in reidentification, the presence of animals with uncertain identification, or the impact of this uncertainty on abundance estimates (Beck 1973; Kato et al. 2003; Hiby et al. 2011; Belsare and Gompper 2014; Tenzin et al. 2015). Then, we interpret that these studies assumed that animals were identified without error and we cannot make comparisons regarding this.

Some capture recapture studies tried to tackle the problem of misidentification but, at the present time, these approaches do not apply to our study. Most of them deals to DNA analysis applied to capture recapture studies, when an error in genetic identification produces a "ghost" animal that does not exist (see Lukacs and Burnham 2005a, Link et al. 2010). What makes different natural mark capture-recapture studies is that individuals not identified in one occasion can be accurately identified in another occasion. In our case, a dog not identified in the first occasion should belong to any of the histories of dogs identified in the first occasion $(100,110,101$ and 111$)$. Worst, dogs may not be identified in two or three sampling occasions, increasing the number of possible combinations of true detection histories for unidentified dogs. Lukacs and Burnham (2005b) assume that two identification errors made at different genetic capturing occasions are assumed to never produce identical genotypes. In our case, we cannot assure if dogs not identified in two or three occasions are in fact the same dog.

Yohizaki (2007) developed an alternative method to the typical multinomial approach used to building likelihood for capture histories. He proposed an unweighted least square for estimate abundance, for situations where misidentification occurs at any capture occasion. He compared estimations using models $M_{0}$ and $M_{t}$ with his statistical approach and modeled the bias in estimation in relation to known abundances. Although the bias depends on the initial abundance value simulated, his scenarios included 1000 individuals as starting values, so the results apply to our case. With levels of capture probabilities similar to ours, and under different probabilities of misidentification $(0.1,0.05,0.025)$, the bias is high at about $40 \%, 20 \%$ and $0.4 \%$ respectively with models $M_{0}$ and $M_{t}$. Looking to our data for each sampling occasion, the probability for an animal not being identified at each occasion is low $(p=0,07, p=0,04$ and $p=0,02$ for the first, second, and third survey respectively).

Another option for dealing with not identified animals would be discard these observations from the capture recapture histories, based on their low frequency. Running MARK without these observations, model $M_{h}$ is still the best model, giving estimates of 1147 dogs (CI 95\% 982-1369). Under this approach, our original estimates should be biased high in $11 \%$. A third approach would be to assign unidentified dogs to the possible detection histories in a random way, and then compute the detection histories to 
estimate abundance. Given the number of unidentified dogs of 15, 9 and 4 for the three surveys, there are 540 possible combinations of detection histories to assign. One example of random assignment retrieved also $M_{h}$ as the best model, with an estimation of 1095 dogs (95\% Cl 995-1223). Under this approach, our original estimates should be biased high in $14 \%$. Given all this information, we assume that the bias in our results should be between $0.4 \%$ and $20 \%$.

The spatial heterogeneity in the number of roaming dogs observed would call for apply a stratified sampling in the design to account for such variability, instead of applying a systematic sampling. However, as one of the outcomes of this work is to give a cognitive product to the city authorities to be applied in future evaluations, we selected and recommend a systematic sampling of permanent transects. These transects can be easily repeatable in the future and can be used as "permanent" stations. On the other hand, covariate-based modeling approaches are progressively replacing stratified sampling approaches, because of the explanatory improvement of modeling in relation to a simple stratification approach (Buckland et al. 2015). Therefore, it is expected that estimates of the abundance of roaming dogs in the future should be based on spatial models. These models enable investigation of interactions between environmental/social covariates and population densities and mapping the spatial distribution of a population help to communicate results to non-experts (Miller et al. 2013). Also, covariates can vary along space and time over a city, together with changes in the population of the city and/or in the welfare of inhabitants.

\subsection{Abundance estimation}

Due to the short time between surveys this study complies with the assumption of a closed population. On the other hand, this study used coloration patterns of dogs for identification, a type of permanent and non-invasive mark, so estimations cannot be affected by loss or retention of marks (Hiby et al. 2013; Nery and Simão 2012). The assumption of constant probability of capture and recapture of individuals among surveys is unlikely, due to several factor affecting capture probabilities. If most dogs are owned, their photographic capture/recapture probability depends largely on human behavior, as people let dogs out. This heterogeneity must be considered in the models; in fact, a recurring criticism of roaming dog abundance estimates is not to consider dogs' probability of detection (Belo et al. 2017). Then, it was pertinent to include a model that accounted for individual heterogeneity of the probability of detection ( $M_{h}$ model). This model was also used by Belsare and Gompper (2013) meanwhile Hu et al. (2019) used models $M_{t}, M_{h}$ and $M_{t h}$ (being $M_{t h}$ a model that combines heterogeneity in time and individuals). In turn, Hiby et al. (2011) used $M_{t}$ as their first and unique choice.

The size of the roaming dog population in Ushuaia was estimated at 12,797 individuals $(95 \% \mathrm{Cl} 10,979$ $15,323)$. The estimate does not correspond to the whole city since about $12.5 \%$ of the surface was excluded from sampling as this area presents a lower density of houses hence it is expected a lower roaming dog density. This estimation must be taken as a minimum estimate and represents the number of dogs that could be roaming at some time of the day. This estimation is lower than the one reported by Garber (2016), when $60 \%$ of the 31922 estimated dogs are roaming at some time of the day $(19,152)$, but 
taking in mind the non-surveyed part of the city, the final numbers could come closer. Given that Ushuaia had around 75,000 inhabitants in 2015 (Molpeceres 2017), the ratio of roaming dog:inhabitants is around 1:6.0 (taking the limits of the confidence interval, 1:7.0 and 1:5.0). The ratio of 1:6.0 dog:inhabitants exceeds the 1:10 ratio recommended by the World Health Organization (Brusoni et al. 2007). Moreover, the WHO value refers to the total number of dogs, which would include supervised, partially supervised and unsupervised dogs. The ratio for Ushuaia is similar to that observed in other areas of the country and the world (Table 2) but as we excluded completely supervised dogs, the final dog:inhabitant ratio should be greater in favor of dogs, which is consistent with the ratio of dog:inhabitants of 1:2,05 provided by Garber (2016).

Table 2

Estimated number of people per dog for different cities and countries of the world (Brusoni et al. 2007).

\begin{tabular}{|ll|}
\hline Place & People per dog \\
\hline Santa Fe de Bogotá, Colombia & 10.9 \\
\hline Belo Horizonte, Brazil & 8.6 \\
\hline Santiago de Chile, Chile & 7.4 \\
\hline Asunción, Paraguay & 6.8 \\
\hline Maracaibo, Venezuela & 6.7 \\
\hline Morón, Argentina & 5.7 \\
\hline Rosario, Argentina & 5.1 \\
\hline Buenos Aires, Argentina & 5.0 \\
\hline Neuquén, Argentina & 5.0 \\
\hline San Martín de los Andes, Argentina & 5.0 \\
\hline General Pico, Argentina & 4.6 \\
\hline Costa Rica & 4.0 \\
\hline United Kingdom & 3.1 \\
\hline
\end{tabular}

\subsection{Abundance index}

As stated by Hiby and Hiby (2017), the number of roaming dogs per kilometer of street should be a useful tool to detect dog population changes over time, changes in citizen behavior regarding the tenure of pets and expose differences between sites in a city. Given our sampling, the difference in density needed between two surveys to detect a significant change in the dog population (with a confidence level of 95\%) is approximately twice the standard error. Then, the smaller the standard error between surveys, the lower the level of change required to detect changes in dog density. To reduce the standard error, the alternatives would be to increase the number of transects to survey and/or reduce the variability of the 
count between transects (encounter rate). However, we observed that increasing the number of transects does not have an impact in reducing the level of change in density required with constant levels of standard error (data not shown), so the greatest effort should be put in reducing the variability in encounter rate between transects.

As the abundance index was not significantly different between surveys, the count from any of the three days could be used as an indicator of the abundance. However, there were differences between transects among surveys, so carrying out a single count could lead to results that do not adequately describe the spatial variability of dogs. Also, as the number of recorded dogs increased with the survey occasion, it is possible that surveyors became more experienced with time for looking for dogs.

\subsection{Factors affecting abundance of dogs}

The demographic, socioeconomic, environmental and cultural factors that explain the differences in the abundance of roaming dogs have not been sufficiently explored so far (Belo et al. 2017). The population of roaming dogs varies between areas in a city and depends on the attitudes of owners and neighbors towards roaming dogs, and on the structure of homes and fencing which in turn are influenced by cultural and economic drivers (Hiby and Hiby 2017). However, our best model included only geographical location, revealing several hotspots in the Ushuaia city. Despite that, the presence of outliers in the data could be forcing the inferences made with this covariate. Two areas named Valle de Andorra and Escondido, yielded 181 different dogs identified in 9 of the 72 transects surveyed, equivalent to $33.6 \%$ of the total number of different dogs identified in $12.5 \%$ of the samples. The geographical location may be the expression of some covariate not measured and merits further studies. Contrary of what was expected, the number of houses did not receive support as a factor. Some authors propose that areas with a lower socioeconomic level and/or with a higher density of houses may have a lager density of dogs and less care for their pets, compared to areas with a higher socioeconomic level (Font 1987; Ochoa et al. 2014; Belo et al. 2015). Likewise, some authors suggest that apartments are the type of residence with lower frequency of roaming dogs (Jensen 2007). The number of waste containers was neither a significant factor, so the availability of food resources in the way of garbage without proper disposal does not seem to favor the number of roaming dogs. The distance to the city limit was neither a significant factor, so the availability of shelters outside the city does not seem to affect the presence of roaming dogs. However, the city can provide multiple shelters and in less severe conditions than the forest out of the city. For example, during the surveys we observed dogs resting under vehicles, at the entrance doors of buildings or even in shelters on the streets expressly built by people. Finally, the number of perimeter fences did not influence the abundance of roaming dogs, so we reject the idea that the lack of perimeter fences favors the presence of dogs.

All this evidence, together with the condition of observed dogs, strongly suggests that the main driver for the presence of roaming dogs on the streets is just the behavior of owners. This is a consequence of a lack of awareness on the part of dog owners (Zumpano et al. 2011), who leave their pets roaming free during some time of the day or the whole day, because they may defecate in the streets instead that doing at home, let them look for food or amusement, make them serve as guardians or simply because 
their holders are absent from the home for several hours. We suggest carrying out social studies to assess the number of households with dogs and the behavior of owners, including their motivations for the possession, adoption or abandonment of these animals, as well as the motivations for let their pets roaming in public spaces.

We present some recommendations for future surveys.

First, we recommend attaching to a systematic design that allows establishing a series of permanent stations for monitoring numbers in the future and adding transects according to the expansion process of the city.

Secondly, we recommend testing the improvement in estimations by increasing the number of occasions of recapture, from three to five for example, as suggested by Pollock (1982). Third, we recommend improving the observation process by increasing the number of observers, reducing the speed of the vehicle or carrying out the search for dogs on foot (for example with one person walking on each sidewalk of a street section). These improvements in the observation process should reduce the nonidentification of dogs, improve the detection histories, reduce the variability between transects and the standard error between surveys and, therefore, reduce the difference in density need to detect a change in the index, improving both the abundance estimation and the estimation of the index.

The abundance estimation differs from the estimation of the index in the extra labor of taking pictures, identify dogs from pictures, the making of the detection history, and the use of the program MARK. In this study, this extra labor demanded less than three days of work in relation of the estimation of the index, which can be done few minutes after the end of a survey. However, in view of the more accurate and precise results, we advocate for the estimation of abundance instead of an index because it delivers a more accurate product at a not very extra expense of effort. For the future we recommend making the estimation every four years, as this frequency ensures that all municipal Major perform an estimation during their term of four years.

\section{Conclusions}

The simulation of survey designs allows drawing samples that accomplish design-based surveys prescriptions. Systematic segmented grid sampling allows establishing permanent transects as sampling stations to monitor numbers along the time.

We estimated a population of free roaming dogs at Ushuaia of at least 12,797 dogs ( $95 \% \mathrm{Cl} 10,979$ 15,323), giving a relationship of dog:humans of 1:6, higher than the 1:10 relationships recommended by the WHO. Dogs exhibit strong spatial heterogeneity in their distribution, with two neighbourhoods standing out, with $33.6 \%$ of the different dogs identified in the $12.5 \%$ of samples.

The abundance index presents large uncertainty due to the spatial heterogeneity in the encounter rate. This affects the difference in density needed to detect changes in density, which reaches twice the standard error of estimates. 
Giving the welfare status of dogs, and the weak relationship with covariates to explain numbers and distribution of dogs (apart from the geographical location), we suggest that the behavior of owners is the main driver for the presence of free roaming dogs in the streets.

The capture-recapture methodology requires a slightly larger effort than the estimation of the abundance index but gives a much more precise estimation than the index. Then, we advocate for the use of a photographic capture-recapture methodology, at least for cities of similar scale to Ushuaia.

This work aims to provide an initial baseline on the number of free roaming dogs in Ushuaia and provide information for future evaluations and monitoring of the canine population conducted by any local government. Furthermore, we hope this information will contribute to the planning and assessment of the effects of interventions, in order to reduce the presence of free roaming dogs in public spaces.

\section{Declarations}

\section{Funding statement}

Funding for the project was provided by the University of Tierra del Fuego (Project PIDUNTDF A 2016-11), by the Agencia Nacional de Promoción de la Ciencia y la Tecnología (PICT 2016-4301). CONICET funded AS and provided support for the analysis of data and writing. None of these institutions participated in the study design, in the collection, analysis and interpretation of data, in the writing of the report, nor in the decision to submit the article for publication.

\section{Conflict of interest}

The authors declare that the research was conducted in the absence of any commercial or financial relationships that could be construed as a potential conflict of interest.

\section{Availability of data and material}

Data are available upon reasonable request. Data include individual dog data identification, DISTANCE projects used for the survey design selection, and data used for modeling dog abundance. Data will be available beginning 9 months and ending 18 months following article publication. Researchers which provide a methodologically sound proposal and are approved by the researches from this study are allowed to reuse this data. Proposals should be directed to aschiavini@wcs.org.

\section{Code availability}

Not applicable.

\section{Author contributions}

Both authors contributed equally to the conception and design of the study, the acquisition of data, the analysis and interpretation of data, the drafting of the article, the critical review and the final approval of 
the version to be submitted.

\section{Acknowledgments}

This work was developed as the dissertation of EA for acquire the degree in Biology at the Universidad Nacional de Tierra del Fuego. To the companies Agrotécnica Fueguina and Correo OCA, for allowing interviewing their personnel. To Milena Mansilla for the interview with ARAF, the dog protection organization, and for borrowing her camera to carry out the surveys. To parents and sister of EA, Adrián Arona, Marisa Ferreira and Agustina Arona, for helping in each survey.

\section{References}

1. Amstrup SC, McDonald TL, Manly BF (2010). Handbook of capture-recapture analysis. Princeton University Press.

2. Akaike $H$ (1973). Information theory and an extension of the maximum likelihood principle. In B.N. Petrov and F. Csaki (Eds.), Proceedings of the $2^{\text {nd }}$ International Symposium of Information Theory. Akadeemiai Kiadi, Budapest, Hungary, 267-281.

3. Anderson D, Burnham K (2004). Model selection and multi-model inference, $2^{\text {nd }}$ ed. New York: Springer-Verlag.

4. Barton K (2019). MuMIn: Multi-Model Inference. R package version 1.43.15/r468. https://R-Forge.Rproject.org/projects/mumin/.

5. Beck AM (1973). The Ecology of Stray Dogs: A Study of Free-Ranging Urban Animals. Baltimore York Press.

6. Belo VS, Struchiner CJ, Werneck GL, Neto RGT, Tonelli GB, de Carvalho Jr et al. (2017). Abundance, survival, recruitment and effectiveness of sterilization of free-roaming dogs: A capture and recapture study in Brazil. PloS One. 12(11). e0187233. https://doi.org/10.1371/journal.pone.0187233.

7. Belo VS, Werneck GL, da Silva ES, Barbosa DS, Struchiner CJ (2015). Population estimation methods for free-ranging dogs: a systematic review. PloS One. 10(12). https://doi.org/10.1371/journal.pone.0144830.

8. Belsare AV, Gompper ME (2013). Assessing demographic and epidemiologic parameters of rural dog populations in India during mass vaccination campaigns. Preventive Veterinary Medicine. 111(1-2): 139-146. https://doi.org/10.1016/j.prevetmed.2013.04.003.

9. Belsare AV, Vanak AT, Gompper ME (2014). Epidemiology of viral pathogens of free-ranging dogs and Indian foxes in a human-dominated landscape in central India. Transboundary and emerging diseases. 61: 78-86. https://doi.org/10.1111/tbed.12265.

10. Brusoni C, Fernández Canigia J, Lara J, Dezzotti A (2007). Tamaño y estructura de la población canina en San Martín de los Andes (Neuquén). Analecta Veterinaria. 27 (1): 11-23.

11. Buckland ST, Anderson DR, Burnham KP, Laake JL (1993). Distance sampling: estimating abundance of biological populations. London: Chapman and Hall. 
12. Buckland ST, Rexstad EA, Marques TA, Oedekoven CS (2015). Distance sampling: methods and applications. New York: Springer.

13. Burnham K, Anderson D (2004). Multimodel Inference - Understanding AIC and BIC in Model Selection. Sociological Methods \& Research. 33(2): 261-304. https://doi.org/10.1177/0049124104268644.

14. International Companion Animal Management Coalition (2015). Are we making a difference? A guide to monitoring and evaluating dog population management interventions. ICAM Coalition, Yarmouth Port.

15. Cochran WG (1977). Smapling techniques. 3th ed. New York: Wiley \& Sons.

16. Daniels TJ, Bekoff M (1989). Population and social biology of free-ranging dogs, Canis familiaris. Journal of Mammalogy. 70(4): 754-762. https://doi.org/10.2307/1381709.

17. Dias RA, Guilloux AGA, Borba MR, Guarnieri MCL, Prist R, Ferreira F, et al. (2013). Size and spatial distribution of stray dog population in the University of São Paulo campus, Brazil. Prev Vet Med. 110(2): 263-273. https://doi.org/10.1016/j.prevetmed.2012.12.002.

18. Font $\mathrm{E}$ (1987). Spacing and social organization: urban stray dogs revisited. Applied Animal Behaviour Science. 17(3-4): 319-328. https://doi.org/10.1016/0168-1591(87)90155-9.

19. Fox J, Weisberg $S$ (2019). An $\{R\}$ Companion to Applied Regression, third Edition. Sage, Thousand Oaks CA. https://socialsciences.mcmaster.ca/jfox/Books/Companion/.

20. WSAVA Nutritional Assessment Guidelines (2011). WSAVA Nutritional Assessment Guidelines. Journal of Feline Medicine and Surgery. 13(7): 516-525. https://doi.org/10.1016/j.jfms.2011.05.009.

21. Hiby E, Atema KN, Brimley R, Hammond-Seaman A, Jones M, Rowan A, et al. (2017). Scoping review of indicators and methods of measurement used to evaluate the impact of dog population management interventions. BMC Veterinary Research. 13(1): 143. https://doi.org/10.1186/s12917017-1051-2.

22. Hiby E, Hiby L (2017). Direct observation of dog density and composition during street counts as a resource efficient method of measuring variation in roaming dog populations over time and between locations. Animals. 7(8): 57. https://doi.org/10.3390/ani7080057.

23. Hiby L, Paterson WD, Redman P, Watkins J, Twiss SD, Pomeroy P (2013). Analysis of photo-id data allowing for missed matches and individuals identified from opposite sides. Methods in Ecology and Evolution. 4(3): 252-259. https://doi.org/10.1111/2041-210x.12008.

24. Hiby LR, Reece JF, Wright R, Jaisinghani R, Singh B, Hiby EF (2011). A mark-resight survey method to estimate the roaming dog population in three cities in Rajasthan, India. BMC Veterinary Research. 7(1): 46. https://doi.org/10.1186/1746-6148-7-46.

25. Hu CH, Yu PH, Kang CL, Chen, HL, Yen SC (2019). Demography and welfare status of free-roaming dogs in Yangmingshan National Park, Taiwan. Preventive veterinary medicine. 166: 49-55. https://doi.org/10.1016/j.prevetmed.2019.03.009. 
26. Hurvich CM, Tsai CL (1989) Regression and time series model selection in small samples. Biometrika. 76(2): 297-307. https://doi.org/10.1093/biomet/76.2.297.

27. Jensen $P$ (2007). The Behavioural Biology of Dogs. The dog in its niche: among humans. Wallingford: CAB International.

28. Lincoln FC (1930). Calculating waterfowl abundance on the basis of banding returns. Washington: US Department of Agriculture.

29. Link WA, Yoshizaki J, Bailey LL, Pollock KH (2010). Uncovering a latent multinomial: analysis of mark-recapture data with misidentification. Biometrics. 66(1): 178-185. https://doi.org/10.1111/j.1541-0420.2009.01244.x.

30. Lukacs PM, Burnham KP (2005b). Estimating population size from DNA-based closed capturerecapture data incorporating genotyping error. The Journal of Wildlife Management. 69(1:396-403. https://doi.org/10.2193/0022-541X(2005)069<0396:EPSFDC>2.0.C0;2.

31. Lukacs PM, Burnham KP (2005a). Review of capture-recapture methods applicable to noninvasive genetic sampling. Molecular ecology. 14(13): 3909-3919. https://doi.org/10.1111/j.1365294X.2005.02717.x.

32. McCullagh P, Nelder Frs JA (1989). Generalized Linear Models, $2^{\text {nd }}$ ed. London: Chapman and Hall.

33. Miller DL, Burt ML, Rexstad EA, Thomas L (2013). Spatial models for distance sampling data: recent developments and future directions. Methods in Ecology and Evolution. 4(11): 1001-1010. https://doi.org/10.1111/2041-210X.12105.

34. Molpeceres C (2017). Repensando el territorio en el fin del mundo. Investigación + Acción. 20(20): 77-100.

35. Nery MF, Simão SM (2012). Capture-recapture abundance estimate of Guiana dolphins in southeastern Brazil. Ciencias Marinas. 38(3): 529-541. https://doi.org/10.7773/cm.v38i3.2012.

36. Ochoa Y, Falcón N, Zuazo J, Guevara B (2014). Estimación de la población de perros callejeros en el distrito de Los Olivos, Lima, Perú. Revista de Investigaciones Veterinarias del Perú. 25(3): 366-373.

37. Otis D, Burnham KP, White GC, Anderson DR (1978). Statistical inference from capture data on closed animal populations. Wildlife Monogrraph. 62: 1-135.

38. Özen D, Böhning D, Gürcan IS (2016). Estimation of stray dog and cat populations in metropolitan Ankara, Turkey. Turkish Journal of Veterinary and Animal Sciences. 40(1): 7-12. https://doi.org/10.3906/vet-1505-70.

39. Pollock KH (1982). A capture-recapture design robust to unequal probability of capture. Journal of Wildlife Management. 46(3): 757-760. https://doi.org/10.2307/3808568.

40. R Core Team (2019). R: A language and environment for statistical computing. R Foundation for Statistical Computing, Vienna, Austria. https://www.R-project.org/.

41. Schiavini A, Narbaiza C (2015). Estado de situación de los conflictos derivados de las poblaciones caninas en Tierra del Fuego. Report presented to the Comité de Emergencia Agroganadero y de Alerta Sanitaria de Tierra del Fuego. Available upon request from author. Ushuaia. 
42. Schnabel ZE (1938). The estimation of the total fish population of a lake. The American Mathematical Monthly. 45(6): 348-352. https://doi.org/10.1080/00029890.1938.11990818.

43. Sutherland WJ (Ed.) (2006). Ecological census techniques: a handbook, second ed. Cambridge: Cambridge University Press.

44. Tenzin T, Ahmed R, Debnath NC, Ahmed G, Yamage M (2015). Free-roaming dog population estimation and status of the dog population management and rabies control program in Dhaka City, Bangladesh. PLoS Neglected Tropical Diseases. 9(5). e0003784. https://doi.org/10.1371/journal.pntd.0003784.

45. Thompson SK (2002). Sampling, $2^{\text {nd }}$ ed. New York: Wiley.

46. White GC, Burnham KP (1999). Program MARK: survival estimation from populations of marked animals. Bird study. 46(sup1): S120-S139. https://doi.org/10.1080/00063659909477239

47. White GC, Burnham KP, Otis DL, Anderson DR (1978). Users manual for program CAPTURE. Utah: Utah State University Press.

48. Williams BK, Nichols JD, Conroy MJ (2002). Analysis and management of animal populations. Academic Press.

49. Yoshizaki J (2007). Use of natural tags in closed population capture-recapture studies: modeling misidentification. Dissertation Doctor of Philosophy Biomathematics and Zoology. University of North Carolina.

50. Zanini F, Leiva D, Cabeza S, Elisondo C, Olmedo E, Pérez H (2008). Poblaciones caninas asilvestradas: impacto en la producción pecuaria de Tierra del Fuego, Argentina. Programa para el Mejoramiento de la Calidad de la Lana (Prolana). Secretaría de Gobierno de Agroindustria, Ministerio de Producción y Trabajo. Argentina.

51. Zumpano R, Tortosa A, Degregorio OJ (2011). Estimación del impacto de la esterilización en el índice de crecimiento de la población de caninos. Revista de Investigaciones Veterinarias del Perú. 22(4): 336-341.

\section{Figures}

\section{Figure 1}

Reference map of the survey area, showing southern south South America, the Tierra del Fuego archipelago and Ushuaia city 


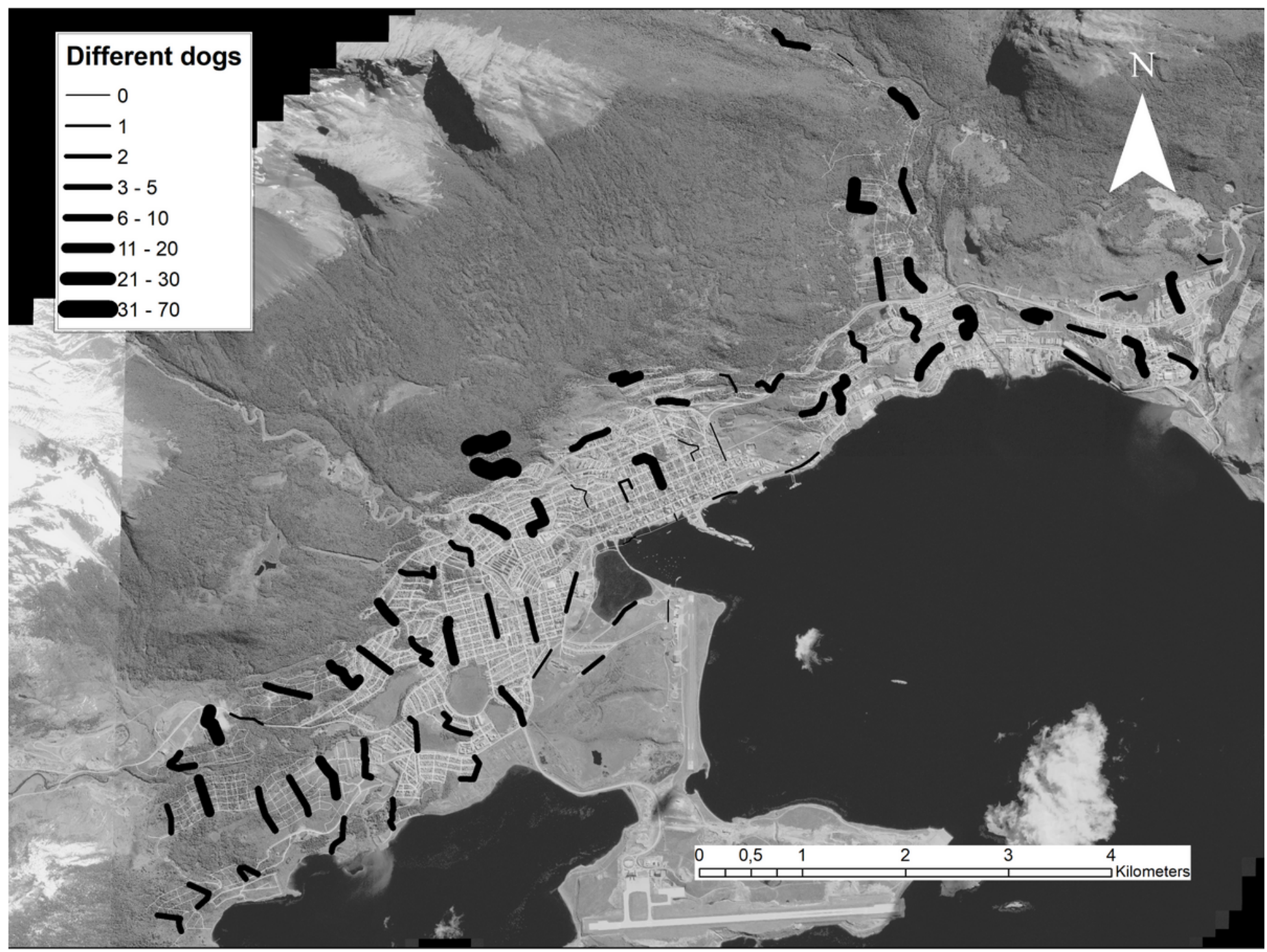

Figure 2

Sum of different dogs identified in each transect along the three surveys 


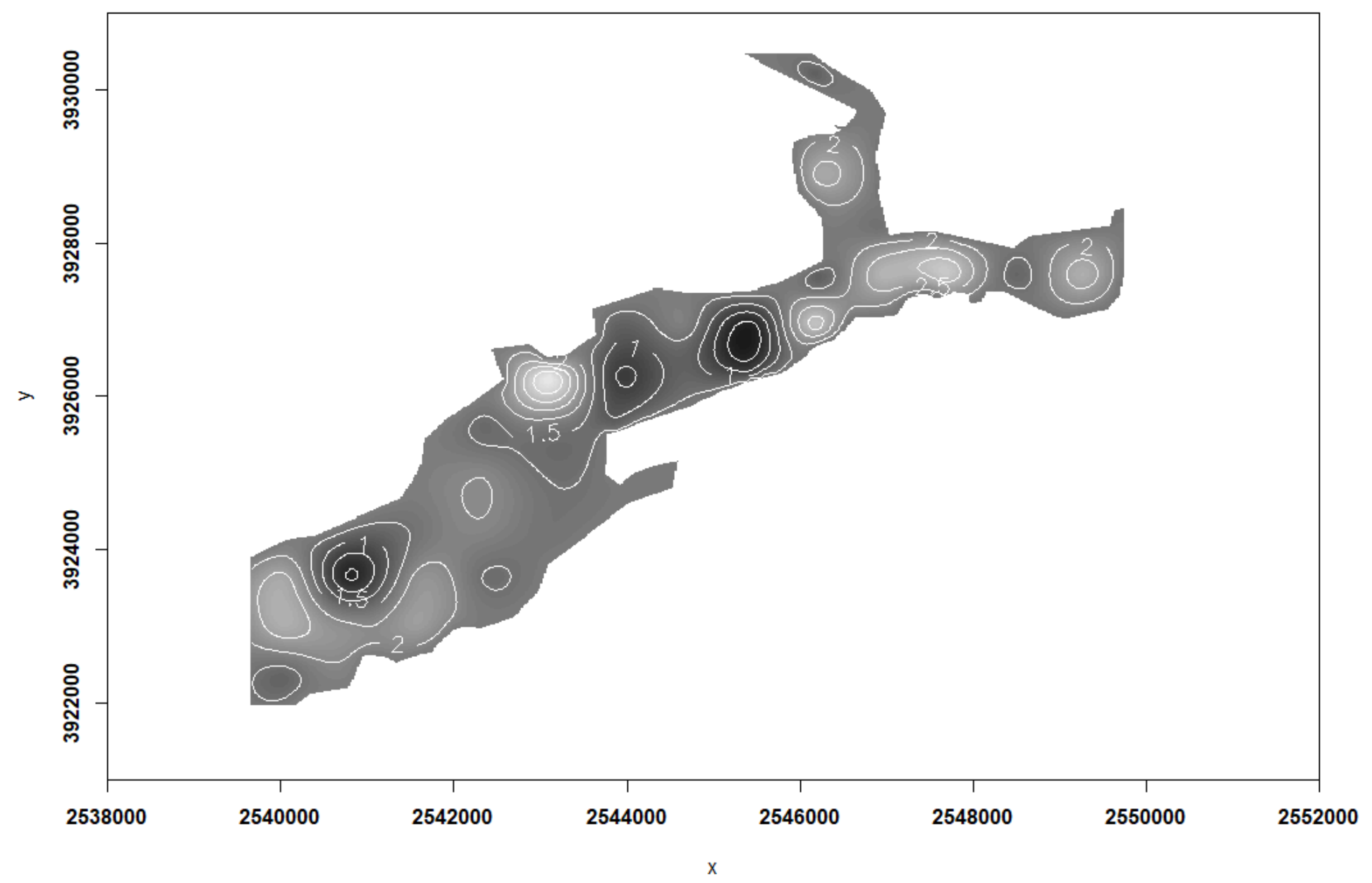

Figure 3

Smooth of geographical location for the sum of different dogs. Lighter areas correspond to lower number of dogs

\section{Supplementary Files}

This is a list of supplementary files associated with this preprint. Click to download.

- S1Fig1Selectedsystematicsegmenteddesign.tif

- S1Fig2Adaptationofthesystematicdesign.tif

- S4Fig3Numberofhouseholds.tif

- S4Fig4Numberoffences.tif

- S4Fig5Numberofwastecontainers.tif

- SupplementalMaterialAronaandSchiavini.pdf 